\title{
BARREIRAS ENTRE AS PERIFERIAS E AS INSTITUIÇÕES DE ENSINO: DIFICULDADE DAS MULHERES EM ACESSAR O CENTRO DE REFERÊNCIA PARA AS MULHERES SUELY SOUZA DE ALMEIDA
}

Rosimar Souza dos Santos Borges ${ }^{1}$, Uisis Rodrigues dos Santos ${ }^{2}$, Isabel Gonçalves da Silva $^{3}$

Resumo: $O$ presente artigo tem por objetivo investigar as condições objetivas e subjetivas que fazem com que as mulheres em situação de violência tenham dificuldades em acessar o Centro de Referência para as Mulheres Suely Souza de Almeida - CRM-SSA, localizado no Campus Universitário da Universidade Federal do Rio de Janeiro (UFRJ), comparando-se ao acesso no Centro de Referência para as Mulheres da Maré (CRMM). O Centro de Referência é um projeto de extensão do Núcleo de Estudos de Políticas Públicas em Direitos Humanos (NEPP-DH), que trabalha com mulheres vítimas de violência, e seu objetivo é prevenir e enfrentar a violência contra a mulher através do resgate da autoestima e autonomia, criando formas para que as mulheres tornem-se agentes de sua própria transformação. Para realização da pesquisa foram coletados dados em ambos os Centros no período de três meses (de junho a agosto de 2017), além de pesquisa em artigos e sites como google acadêmico, BVS-Bireme, MEDLINE, PubMed entre outros. Encontramos como resultado dos estudos profundas disparidades no que diz respeito ao perfil das usuárias, demandas e fluxo de atendimento em cada um dos centros. Associamos tais disparidades à questão do território e direito à cidade, à elitização da universidade pública, ao racismo estrutural, entre outros fatores.

Palavras chave: Mulheres. Centros de Referência. Espaço urbano. Universidade pública. Violência de gênero.
Abstract: The present article have the object to investigate the subjects and objective condicions that make with

\footnotetext{
${ }^{1}$ Mestre em Saúde Coletiva, graduada em Serviço Social e Direito, Assistente Social da Universidade Federal do Rio de Janeiro (UFRJ), atua no Centro de Referência para as Mulheres Suely Souza de Almeida (CRM-SSA)

${ }^{2}$ Graduanda em Serviço Social na Universidade Federal do Rio de Janeiro (UFRJ), extensionista do Proext no Centro de Referência para as Mulheres Suely Souza de Almeida (CRM-SSA).

${ }^{3}$ Graduanda em Serviço Social na Universidade do Estado do Rio de Janeiro (UERJ), estagiária no Centro de Referência para as Mulheres Suely Souza de Almeida (CRM-SSA)
} 
women in a violence situacion have difficult in access the Center Reference to the Woman Suely Souza de Almeida (CRMSSA), localized in the campus of the Federal University of Rio de Janeiro (UFRJ), comparing to the access in the Center Reference to the woman in Maré (CRMM). The Center Reference is an extension project of the core studies of public politics in human rights (NEPP-DH), that works with woman victms of violence and your object is prevent and confront the violence against the woman throght the rescue of self-esteem and autonomy, making ways to the woman become agents of your own transformation. For the accomplishment of the research were collected data in both centers in the period of three months (from June until August of 2017), besides of research in articles and sites like academic google, BVS - Bireme, MEDLINE, PubMed, and others. We found like result of the deep studies disparities with regart to the users profile, demands and service flow in each one the Centers. We associate these disparities to the territory and rights to the city, to elitism of the public university, to the structural racism, among other facts.
Key-words: Women. Reference Centers. Urban space. Public university. Gender violence

\section{Introdução}

A violência contra a mulher é uma expressão da questão social que permeia as relações políticas, culturais e econômicas. Tal violência é um problema de ordem estrutural, cuja raiz está na forma patriarcal na qual nossa sociedade é fundada. As desigualdades construídas a partir das relações hierárquicas subjugam a mulher em relação ao homem, e tais relações se dão tanto no âmbito público como no privado (Silva e Soares, 2016).

A partir de 2006, com a sanção da Lei de número 11.340, foi promulgada a Lei Maria da Penha, que passa a criminalizar a violência contra a mulher. Ela é tipificada pelo Estado de cinco formas: violência física, sexual, psicológica, moral e patrimonial. A partir desta lei, se estabelecem serviços de atendimento à mulher em situação de violência, como os Centros de atendimento integral e multidisciplinar, e casas-abrigos ${ }^{4}$, por exemplo.

Ressalta-se que serviços voltados para as mulheres já eram pensados e 
desenvolvidos antes da Lei, como é o caso do Centro de Referência de Mulheres da Maré - Carminha Rosa (CRMM-CR), situado na Vila do João, Complexo da Maré. O CRMM-CR foi implantado no ano 2000 na Vila do João, tendo como objetivo ampliar e assegurar as condições de exercício da cidadania das mulheres moradoras do bairro da Maré. Foi uma iniciativa da Secretaria Especial de Direitos Humanos (SEDH) e da ONG Cidadania, Estudo, Pesquisa, Informação e Ação (CEPIA), financiado pelo Fundo das Nações Unidas para a Mulher (UNIFEM).

Já o Centro de Referência para Mulheres Suely Souza de Almeida (CRMSSA), situado no campus da Universidade Federal do Rio de Janeiro (UFRJ), na Ilha do Fundão, teve sua criação proposta em 2004, durante o governo Lula. Ele surge após avaliação da necessidade de ampliar o trabalho desenvolvido pelo CRMM-CR e com apoio e financiamento da Secretaria Especial de Políticas para as Mulheres da Presidência da República (SPM), num acordo firmado entre esta e a UFRJ. Desde então sua construção se iniciou, e só foi inaugurado em março de 2016. Localizado na Cidade Universitária (Ilha do Fundão), é próximo do complexo da Maré, da Ilha do Governador e outros bairros, como Ramos, Olaria, Bonsucesso, etc., favorecendo (pelo menos geograficamente) o acesso das mulheres destas regiões da zona norte do Rio. O Centro é aberto ao atendimento de mulheres de qualquer localidade, seja por demanda espontânea ou referenciada.

Ambos os Centros estão vinculados ao Centro de Filosofia e Ciências Humanas (CFCH/UFRJ), como um projeto de extensão do Núcleo de Estudos de Políticas Públicas em Direitos Humanos (NEPPDH). Buscam fortalecer a cidadania das mulheres com vistas para os Direitos Humanos, oferecendo atendimento integral, acompanhamentos e orientações para as mulheres que sofrem, sofreram ou estão ameaçadas de violência. Atuam na prevenção e no enfrentamento à violência de gênero em suas variadas formas, buscando trabalhar com este tema de forma crítica, relacionando os casos à totalidade social, a qual está submersa em um contexto de subalternização das mulheres de maneiras diversas. Buscam a superação do quadro por via de uma perspectiva emancipatória.

Os Centros de Referência trazem como diferencial dos outros serviços de atendimento sua vinculação a uma Universidade Federal. Isso faz com que estejam apoiados no tripé que sustenta a educação pública: o ensino, a pesquisa e a extensão. Essa característica possibilita a articulação de políticas públicas para mulheres, bem como também proporciona 
um espaço de formação para os profissionais, pesquisadores e alunos envolvidos com o tema.

No entanto, apesar de os Centros trabalharem de forma articulada e terem os mesmos objetivos, há profundas disparidades no acesso das mulheres ao atendimento em ambos os serviços. As particularidades se revelam através das diferenças no perfil das mulheres atendidas e em suas demandas. A hipótese do trabalho é a de que tal diferença é consequência do espaço urbano: enquanto um Centro de Referência está na periferia, no bairro da Maré, o outro está dentro de um campus universitário - um ambiente que historicamente é elitizado, visto ser um lugar privilegiado para os estudantes de classe média, que tiveram melhores condições de estudo, obtendo êxito nos processos seletivos de ingresso nas universidades públicas.

Entendemos, assim como Corrêa (1989), que o espaço urbano é expressão da complexa estrutura social em classes. Ele se constitui de diversas formas, e ao mesmo tempo em que é fragmentado, também se mostra articulado. Por ser reflexo social e fragmentado, o espaço urbano é profundamente desigual. Ele é a representação tanto das ações do presente, como aquelas que se realizaram no passado deixando marcas nas formas espaciais do
98

presente. Na concepção do autor, portanto, o espaço da cidade capitalista reflete a complexa estrutura social em classes.

Explicar o esvaziamento do Centro de Referência localizado na Ilha do Fundão requer muito mais que uma leitura geográfica pura e simples, importa compreender como as relações sociais perpassadas na Cidade Universitária distanciam as mulheres do acesso ao CRMSSA. Muito além do limite físico, o espaço urbano também é composto por uma dimensão simbólica, "variável segundo diferentes grupos sociais, etários, etc" (Corrêa, 1989:9). É a partir desse entendimento que analisaremos neste trabalho as dimensões que contribuem para o distanciamento das mulheres no tocante ao acesso ao Centro de Referência para as Mulheres Suely Souza de Almeida.

\section{Dificuldades Das Mulheres Em Acessar O CRM-SSA: A Quem Pertence O Espaço Acadêmico?}

Ao analisar a questão do território, podemos afirmar que o Rio de Janeiro hoje é uma cidade muito fragmentada. De acordo com Salgueiro (1998), a cidade industrial do século XIX apresentava muita segregação, pois era constituída por áreas socialmente homogêneas. Desta forma, os bairros populares eram segregados em seu 
determinado lugar, nas "periferias malequipadas e monótonas" (Salgueiro 1998:40), distanciados dos centros onde havia muitas atividades econômicas. A cidade, portanto, era "arrumada". No entanto, este cenário muda no pós-guerra, especialmente após os anos 70 com o desenvolvimento das forças produtivas ${ }^{5}$, mudando assim a forma de apropriação dos territórios. O aumento da mobilidade e da diversidade permite uma fragmentação cada vez maior da estrutura social urbana, misturando as zonas centrais com as periféricas, em um aspecto de continuidade:

$O$ fato de defendermos que a cidade fragmentada substitui a cidade segregada não quer dizer que desapareçam as situações de segregação socioespacial. Em primeiro lugar, porque a fragmentação pode ser vista como uma segregação à escala micro, um patchwork ou manta de retalhos em vez da organização em grandes manchas. (Salgueiro, 1998: 42)

Através desta perspectiva podemos analisar a Cidade Universitária, que mesmo localizada entre bairros da zona norte do Rio de Janeiro e próxima a diversas comunidades (como por exemplo os complexos da Maré e do Alemão), é um espaço historicamente elitizado.

Por isso, fica isolado em relação à população adjacente, que não frequenta $o$

5 Conceito de Marx que diz respeito ao potencial produtivo de uma determinada sociedade. campus universitário devido à elitização do ensino superior brasileiro (principalmente no nosso atual contexto de ofensiva neoliberal, no qual está ocorrendo a retirada de direitos e tentativa de mercantilização das universidades). Sobre o acesso à educação, Andrade (2012:26) afirma:

A principal determinante no acesso à
educação é a renda familiar, embora a
variável cor autodeclarada apresenta
influência no acesso para as
populações de todas as faixas de
renda. Em todas as etapas de ensino e
quintis da renda observa-se que os
não-brancos têm menos acesso à
educação do que os brancos. Assim, de acordo com os gráficos que apontam os dados obtidos através de pesquisa, o perfil das usuárias do CRMM é justamente este excluído do espaço acadêmico. Essas mulheres, em sua maioria, se encontram isoladas na Maré, pois têm seu direito à cidade negligenciado. Segundo Burgos (2005:192) a cidade produz indivíduos cuja "subjetividade encapsulada no interior dos muros dos territórios" os forja com poucas referências do direito à cidade. Assim o indivíduo passa a ter uma sociabilidade ambígua,

pois o território é, de um lado, fonte de toda sorte de violência, que prospera na exata medida em que faltam os direitos, e, de outro, uma dimensão que o envolve e protege das forças desumanas do mercado; ao mesmo tempo que o priva da cidade, o território oferece-lhe alguma forma de 
acesso à comunidade (Burgos, 2003:88-89). Daí se explica o sempre renovado sentimento de lealdade que boa parte de seus moradores nutre pelas instituições locais." (Burgos, apud Burgos, 2005:192)

A partir disso, entendemos o porquê do grande fluxo de atendimentos do Centro situado no complexo da Maré, em detrimento do CRM localizado na Ilha do Fundão. A relação com o território incide nas relações com as instituições locais. A "lealdade", nesse sentido, pode ser explicada através do fato de que as políticas sociais nesse território se apresentam de forma fragmentada e escassa, transformando o Centro de Referência em polo de atendimento social, para além da questão da violência.

É importante ressaltar que tal fenômeno não se restringe à Maré, mas ocorre no bairro dentro da mesma tendência de todas as comunidades do Rio de Janeiro ${ }^{6}$, no que diz respeito ao perfil sociodemográfico (raça, renda, escolaridade, etc.) dos moradores $^{7}$, à

6 Centro de Estudos de Segurança e Cidadania (CESeC). Perfil sociodemográfico dos moradores de favelas com UPP na cidade do Rio de Janeiro, 2016. Disponível em https://www.ucamcesec.com.br/wpcontent/uploads/2016/03/Perfilsociodemogr\%C3\%A1fico-dos-moradores-defavelas-com-UPP.pdf

7 A pesquisa realizada pelo Centro de Estudos de Segurança e Cidadania (CESeC) em 2016 mostra que $77,05 \%$ dos moradores das favelas
100

escassez de políticas públicas, entre outros fatores.

Desta forma, o perfil das mulheres atendidas no CRMM, assim como o de todos os moradores das comunidades do município do Rio, é justamente o perfil excluído do acesso às instituições de ensino superior - e, consequentemente, do ambiente acadêmico dos campi universitários, os quais foram historicamente construídos para as classes mais abastadas.

Ermínia Maricato (2000:12) diz que na cidade ilegal ${ }^{8}$ (nas comunidades), não há planos, nem ordem. E que todo o investimento público está destinado ao que ela chama de cidade formal:

[...] Os serviços de manutenção das áreas públicas, da pavimentação, da iluminação e do paisagismo, aí são eficazes. Embora os equipamentos sociais se concentrem nos bairros de baixa renda, sua manutenção é sofrível. A gestão urbana e os investimentos públicos aprofundam a concentração de renda e a desigualdade. Mas a representação da "cidade" é uma ardilosa construção ideológica que torna a condição de cidadania um privilégio e não um direito universal: parte da cidade

de todas as regiões do município do Rio de Janeiro são negros. $49,8 \%$ dos moradores possuem renda de 1 a 3 salários mínimos, e apenas $2,3 \%$ da população dessas favelas possuem ensino superior completo.

8 Segundo Maricato, ilegal por não caber no contexto do mercado imobiliário formal/legal, nos levantamentos elaborados pelo IBGE (Instituto Brasileiro de Geografia e Estatística), pelos órgãos municipais de aprovação de projetos, etc. (MARICATO, 2000) 
toma o lugar do todo. (Grifo nosso. Maricato, 2000:165)

A desigualdade, nesse sentido, dá bases para a construção de uma cidade fragmentada. $\mathrm{O}$ não pertencimento e $\mathrm{o}$ distanciamento que determinada população tem do que é entendido como cidade, segundo Maricato, é uma construção ideológica onde a cidadania torna-se privilégio e não um direito universal, fazendo com que partes da cidade pertença à alguns e não a todos.

Assim, as mulheres dos bairros populares adjacentes, como Bonsucesso, Ramos, Olaria, Maré, Manguinhos, etc., não se reconhecem como portadoras do direito à cidade e tampouco do direito à educação superior, o que dificulta o acesso dessas mulheres ao Centro de Referência localizado no campus da UFRJ. Portanto, nossa hipótese é a de que o ambiente acadêmico as intimida e afasta, pois faz com que pensem que o atendimento é oferecido apenas para quem possui vínculo com a universidade.

\section{Análise Dos Dados}

Nesta seção iremos desenvolver uma análise dos dados coletados em ambos os Centros no período de três meses (de junho a agosto de 2017), referente ao fluxo das usuárias. Além disso, analisaremos o perfil das usuárias atendidas e as demandas apresentadas. Servirá de demonstração empírica da análise feita na seção anterior.

\section{Comparação Do Fluxo De Usuárias Em Cada Centro (CRM E CRMM)}

Para analisar o fluxo, primeiramente é necessário compreender como é feito o atendimento nos Centros de Referência. No primeiro momento ocorre o acolhimento, nos moldes da Norma Técnica de Uniformização dos Centros de Referência de Atendimento à Mulher em Situação de Violência (2006:33):

A mulher em situação de violência que
espontaneamente buscar ou for
encaminhada ao Centro de Referência
será inicialmente atendida pela equipe
administrativa que oferecerá a ela
informações gerais sobre o Centro de
Referência e sobre a Rede de
Atendimento, esclarecerá suas
dúvidas e verificará o seu interesse em
ter uma entrevista individual com a
dupla de profissionais do atendimento
inicial.

Após o acolhimento, caso haja interesse, a mulher passa pelo atendimento inicial, que é uma entrevista com uma escuta "qualificada, respeitosa e não julgadora" (p. 34), feita por um profissional de plantão - portanto sem necessidade de agendamento. Neste atendimento a demanda é ouvida e atendida, seja por meio de informações, orientações e encaminhamentos. Há também o acompanhamento do caso, em atendimentos que são chamados de retorno. Os retornos 
são atendimentos semanais, realizados por meio de agendamento. É uma forma de acompanhar a mulher no processo de romper com o ciclo da violência, através de seu empoderamento enquanto sujeito de direito. Esses atendimentos são realizados pelo profissional mais adequado à situação, seja o psicólogo, o assistente social ou ambos em atendimento conjunto.

\section{Gráfico 1}

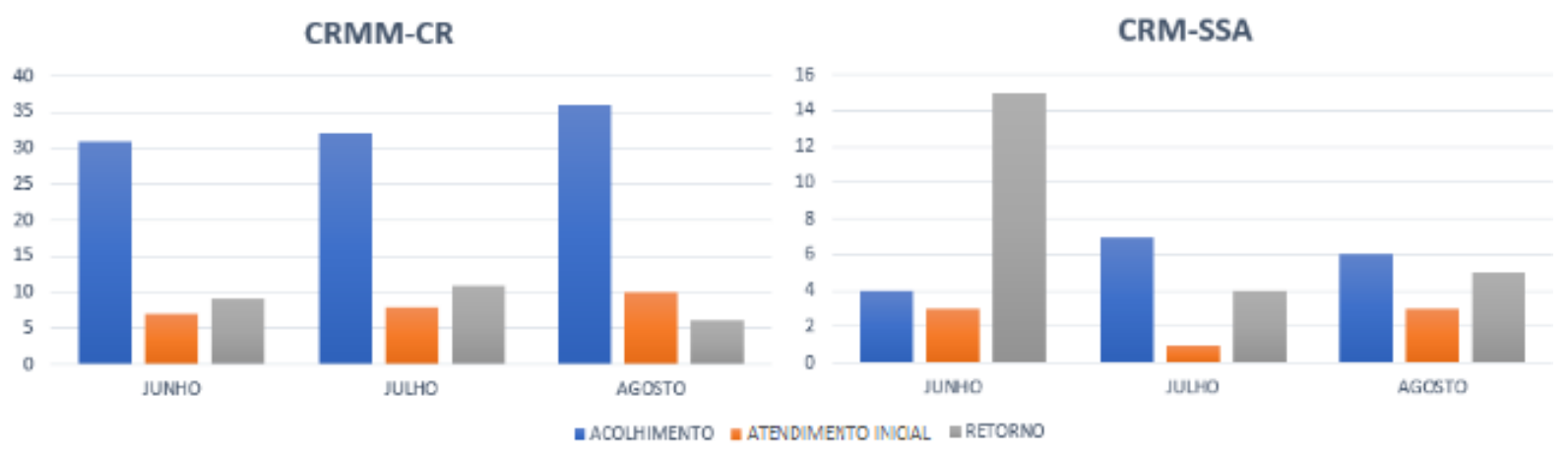

Fluxo de usuárias em cada Centro

Em ambos os Centros percebemos que os atendimentos iniciais não têm número tão expressivo quanto os acolhimentos. No CRMM há uma média de 8 atendimentos novos por mês. $\mathrm{O}$ número de retornos (acompanhamentos) é próximo ao dos atendimentos iniciais. Esses acompanhamentos são geralmente realizados pelo psicólogo da equipe. Já no CRM há uma média de 3 novos atendimentos - um número muito reduzido, em comparação com o CRMM. Há no entanto uma semelhança no que se refere ao número de acompanhamentos. No CRM e no CRMM a média de acompanhamentos chega a ser de 8 mulheres.

Conforme podemos observar no gráfico acima, nos meses de junho, julho e agosto de 2017, tivemos um maior fluxo de acolhimentos e atendimentos iniciais no CRMM comparando-se ao CRM. Isto ocorre porque várias mulheres chegam diariamente ao CRMM por motivos diversos: para pedir informações e orientações sobre seus direitos, pedir o endereço ou telefone de outra instituição, perguntar os dias e horários das oficinas oferecidas pelo Centro, procurar 
atendimento jurídico ou psicológico, etc. Nem sempre a demanda inicial é uma situação de violência, pois esta apresentase, geralmente, mascarada de outras necessidades. Já no CRM dificilmente a mulher chega ao Centro para pedir informações, pois frequentemente ela vem referenciada com a demanda da violência.

Um dos fatores que facilitam o fluxo das usuárias nos acolhimentos no CRMM é o fato de o Centro ficar no mesmo terreno que o posto de saúde da região. Assim, quando essas mulheres vão ao posto, passam em frente ao Centro, o que as leva a conhecê-lo. Já no CRM, por estar situado em um campus universitário, encontra-se velado dentro dos muros da academia.

\section{Comparação Do Perfil Das Mulheres Atendidas}

Aqui analisaremos especificamente o perfil das mulheres atendidas no acolhimento, no mesmo período. A análise mostra as diferenças sociais das mulheres atendidas em cada centro. Foram utilizados quatro aspectos para comparação: local de moradia, raça ${ }^{9}$, renda e escolaridade. Tais aspectos são cruciais para obtermos um panorama social das usuárias.

Gráfico 2

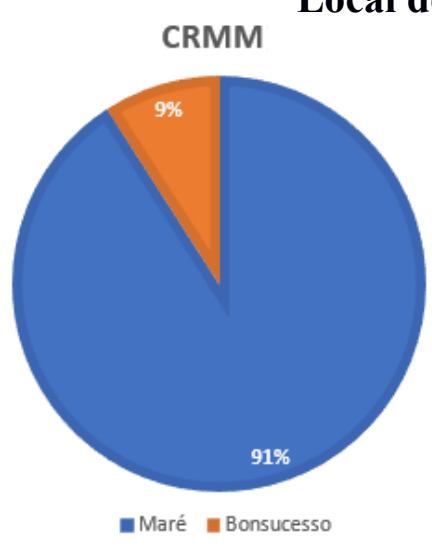

- Maré Bonsucesso

No que diz respeito ao local de moradia das usuárias, é notável que no CRMM as mulheres atendidas são, quase em sua totalidade, moradoras do próprio Complexo

9 Utilizaremos aqui raça não como um conceito biológico de hierarquização, mas como conceito para explicar a "complexidade

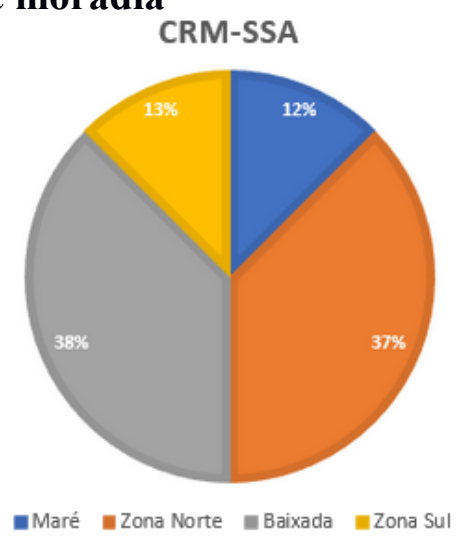

da Maré. Isso porque o Centro de Referência foi criado com o objetivo de atender as moradoras da região e ampliar suas condições de exercício da cidadania.

existente nas relações entre negros e brancos no Brasil”. (GOMES, 2012) 
Em geral, as mulheres residentes do bairro Bonsucesso são familiares de moradores da Maré, ou ex-moradoras da comunidade.

Já o CRM-SSA atende mulheres de diversos bairros e municípios do Rio de Janeiro. O mesmo objetiva um atendimento para todas as mulheres, não só do Estado do Rio de Janeiro, mas também para todo o
Brasil. Atende tanto por demanda espontânea quanto através de encaminhamentos. $\mathrm{O}$ acesso ainda está em fase de expansão, visto que é pouco conhecido, pois funciona há cerca de um ano e meio - além de outros aspectos que serão analisados a seguir.

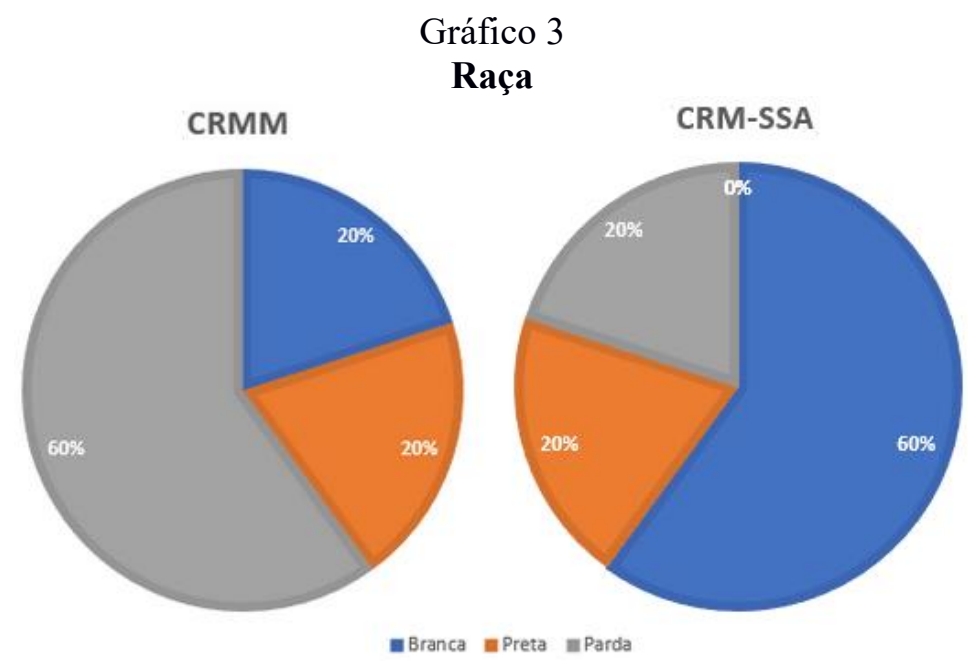

Os dados referentes à raça foram gerados a partir da autodeclaração das usuárias. Com base nisso, nota-se que a maior parte das mulheres atendidas no CRMM são negras ${ }^{10}$ : apenas $20 \%$ das usuárias são brancas. Por outro lado, o gráfico do CRM-SSA mostra que $60 \%$ das mulheres são branca. Não há registros de indígenas ou amarelas ${ }^{11}$ (asiáticas).

10 Entendemos como negras as mulheres que se declaram pretas e pardas, assim como classifica o Instituto Brasileiro de Geografia e Estatística (IBGE).
Segundo Lélia Gonzalez (1982: p.15),

O lugar natural do grupo branco dominante são moradias amplas, espaçosas, situadas nos mais belos recantos da cidade ou do campo[...]. Já o lugar natural do negro é o oposto, evidentemente: da senzala às favelas, cortiços, porões, invasões, alagados e conjuntos "habitacionais" (cujos modelos são os guetos dos países desenvolvidos) dos dias de hoje, o critério também tem sido simetricamente o mesmo: a divisão racial do espaço.

11 Categorias raciais adotadas pelo Instituto Brasileiro de Geografia e Estatísticas (IBGE) desde o Censo Demográfico de 1991: branco, preto, amarelo, pardo e indígena. 
A partir disso entendemos que o território, além de refletir a estrutura social em classes (Corrêa, 1989), reflete também as questões raciais estruturantes em nossa sociedade. Assim podemos entender que a predominância de mulheres negras atendidas na Maré, em oposição às mulheres brancas usuárias do centro localizado na Ilha do Fundão, tem raízes históricas.

Gráfico 4

Escolaridade

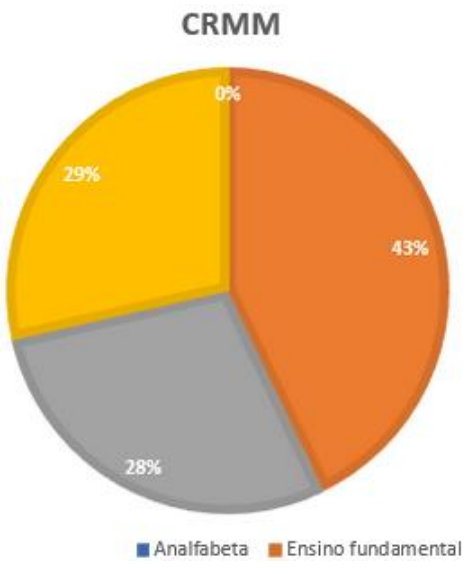

analfabeta $\equiv$ Ensino fundament

No CRMM-CR, a maioria das usuárias possui ensino fundamental, seja ele completo ou incompleto, enquanto no CRM-SSA a prevalência é do ensino superior, boa parte em andamento na própria UFRJ. A baixa escolaridade das mulheres do CRMM-CR pode ser justificada pelo fato de que as usuárias são em sua maioria mulheres negras, conforme dados do Relatório das Desigualdades de Raça, Gênero e Classe, do Grupo de Estudos Multidisciplinares da Ação Afirmativa (GEMAA, 2017).

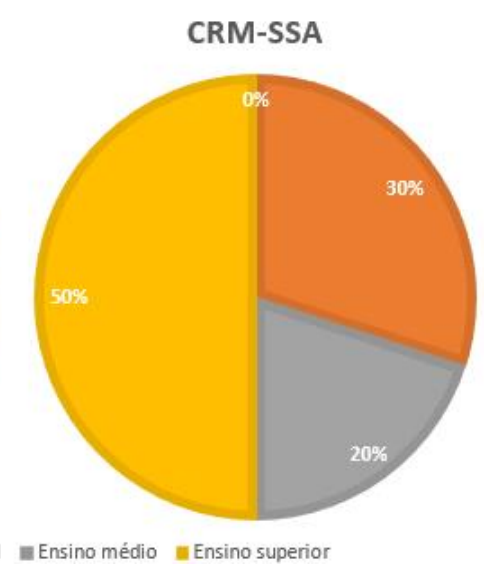

Segundo Suelaine Carneiro (2016), o percurso realizado pelas mulheres na esfera da educação é marcado "por interrupções, abandonos, obstáculos e a necessidade de criar rotas alternativas para realizar o direito à educação". O Relatório das Desigualdades de Raça, Gênero e Classe, do Grupo de Estudos Multidisciplinares da Ação Afirmativa (GEMAA, 2017), utilizou dados da Pesquisa Nacional por Amostra de Domicílios (PNAD) ${ }^{12}$, e nos mostra que a partir do recorte gênero e raça, as mulheres

12 Referente aos anos de 2011, 2012, 2013, 2014 e 2015. 
brancas e não brancas em seus respectivos grupos de cor, estudam por mais tempo que os homens. Entretanto, as mulheres brancas possuem mais anos de formação do que as negras, cuja média percentual alcançou em 2015, 8,4 anos para mulheres negras e 8,3 para as pardas, ao passo que a média para mulheres brancas foi de 10 anos $^{13}$.

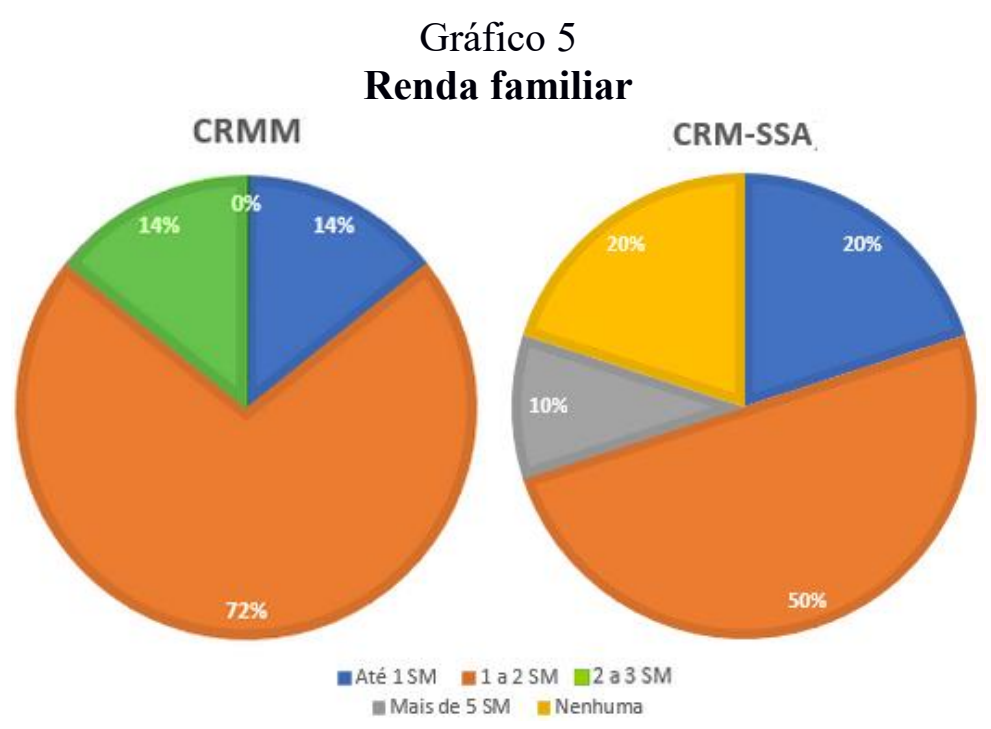

A partir dos gráficos acima, podemos perceber que a renda da maioria das usuárias de ambos os centros é igual: entre 1 e 2 salários mínimos. Entretanto, no CRM-SSA há uma maior variação: $20 \%$ não tem renda, enquanto $10 \%$ tem renda mensal de mais de 5 salários mínimos. Um dos fatores de tal variação se expressa no fato de que são atendidas servidoras da Universidade, assim como estudantes da UFRJ sem renda própria ou bolsa-auxílio. Isso reflete o fato de que a comunidade

13 O Relatório das Desigualdades de Raça, Gênero e Classe; GEMAA, 2017: disponível em: acadêmica é heterogênea em aspectos diversos.

No CRMM, a maior renda vista no período analisado é de 3 salários mínimos, desta forma entendemos que a educação está intimamente ligada à situação socioeconômica das usuárias. $72 \%$ tem entre 1 e 2 salários mínimos. Considerando que $80 \%$ das usuárias do Centro localizado no complexo da Maré são negras, e apenas $29 \%$ delas tem ensino superior, é possível constatar que o distanciamento da educação

http://gemaa.iesp.uerj.br/relatorios/relatoriodas-desigualdades-gemaa-no-1/. 
e o recorte de raça nos ajudam a entender a

desigualdade presente nessa relação entre

COMPARAÇÃO DAS DEMANDAS os dois Centros.

\section{APRESENTADAS}

\section{Gráfico 6}

\section{Demandas apresentadas}

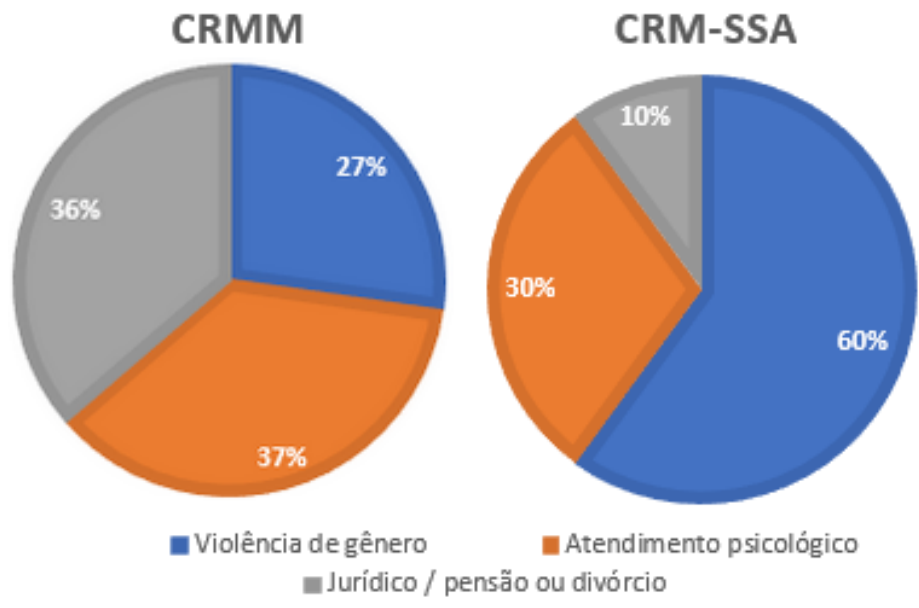

No CRMM, apenas $27 \%$ das jurídicas (encaminhamento para a demandas se referem diretamente à Defensoria Pública para pedido de divórcio violência de gênero, enquanto o CRM-SSA é procurado principalmente por mulheres em situação de violência ( $60 \%$ dos casos). Entretanto, há algumas observações a serem feitas.

No CRM-SSA a violência de gênero - que não é apenas violência física, conforme dito anteriormente - aparece como demanda primária, que se desdobra em outras demandas como atendimentos psicológicos e jurídicos. No CRMM ocorre o contrário: aparecem em primeiro lugar demandas diversas, como atendimento psicológico ou pedidos de informações ou pensão), as quais possuem situações ocultas de violência que vêm a ser descobertas posteriormente. A omissão da situação de violência ocorre por motivos de vergonha, falta de informação, medo, situação de risco, receio de que alguém conhecido que também frequenta o Centro descubra, etc.

Além disso, há todo tipo de procura no CRMM - das informações jurídicas mais básicas aos encaminhamentos mais complexos para unidades de saúde simplesmente porque no bairro da Maré as políticas públicas se apresentam de forma 
escassa e fragmentada, o que torna o Centro de Referência um alvo para inúmeras demandas sociais.

De acordo com as demandas analisadas neste recorte temporal, em todos os casos que envolvem situações de violência de gênero no CRMM se trata de violência doméstica/exercida pelo parceiro, enquanto no CRM são violências variadas ligadas ao gênero, que nem sempre são domésticas: violência extrafamiliar, violência institucional, estupro, abuso de autoridade no trabalho, etc.

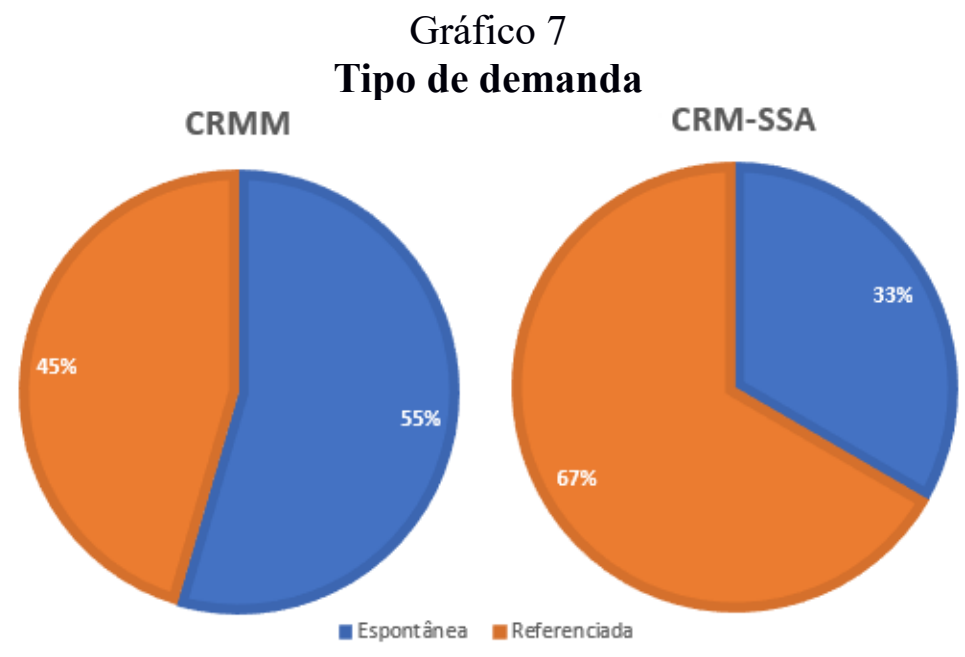

Quanto ao tipo de demanda, no Centro de Referência de Mulheres da Maré é equilibrado, pois o número de demandas referenciadas e espontâneas é próximo: $55 \%$ das demandas são espontâneas e $45 \%$ são referenciadas.

Por outro lado, o Centro de Referência para Mulheres Suely Souza de Almeida conta com $67 \%$ de demandas referenciadas, o que significa que a maioria das usuárias toma conhecimento sobre o Centro por meio de encaminhamentos. Os $33 \%$ de demandas espontâneas são compostos, em geral, por quem já frequenta a Cidade Universitária - e este fato foi o que impulsionou a nossa pesquisa.

\section{Considerações Finais}

Ao analisarmos os dois Centros de Referência para Mulheres, constatamos que os mesmos trabalham de forma articulada, porém em condições muito díspares. Confirmamos nossa hipótese de que um dos motivos do afastamento das mulheres do CRM-SSA é sua localização em um campus 
universitário. $\mathrm{O}$ ensino superior elitizado dificulta o acesso de determinada população, principalmente dos negros. Soma-se a isto o fato de que o espaço urbano do Rio de Janeiro é profundamente fragmentado. Desta forma, apesar de a Cidade Universitária se localizar entre diversas comunidades, ela se torna um espaço restrito distante da maioria da população, pois é velada pela ambiência acadêmica.

Assim, para além do caráter geográfico dos referidos Centros, a questão ideológica do espaço urbano é determinante para o não-acesso de uma população específica aos serviços prestados em territórios tidos como não pertencentes a uma determinada classe, raça, etc. Villaça (2011) nos diz que a segregação urbana só pode ser entendida a partir das desigualdades. Com base nisso, nossa pesquisa empírica buscou demonstrar que os aspectos socioeconômicos e as relações sociais desiguais nos revelam muito sobre essa expressão da questão social, que distancia mulheres dos serviços públicos.

Portanto, conclui-se que um dos motivos pelos quais as mulheres cujo perfil é mais aproximado daquele analisado no CRMM não acessam o CRM é o distanciamento do universo acadêmico dessas minorias devido ao racismo institucional e ao elitismo dentro das
109

universidades, que ocasionam a falta de perspectiva de acessar o ensino superior. A partir disso, ocorre uma certa intimidação de entrar em um campus universitário para atendimento, pois são ideologicamente levadas a crer que é necessário um vínculo com a Universidade: acreditam que o Centro só atende servidoras e alunas. Consequentemente, não se veem como sujeitas de direito ao acesso a esta política pública.

Diante deste panorama, sugere-se o fortalecimento e a integração da rede de proteção à mulher, garantindo informações, divulgação dos serviços, atendimentos de qualidade e o encaminhamento aos serviços especializados, tais como o CRM-SSA. Pois quanto mais divulgação e informação, mas liberdade de acesso a mulher terá. Talvez, esta estratégia seja uma forma de facilitar e promover o acesso ao CRM-SSA e a outros Centros de Referência que estejam localizados dentro de Universidades, e assim, desmistificar a questão do elitismo tão presente nas universidades públicas. 


\section{Referências Bibliográficas}

ANDRADE, C. Y. Acesso ao ensino superior no Brasil: equidade e desigualdade social. Revista Ensino Superior Unicamp, Campinas, n. 6, jun./set., p. 18-27, 2012. Disponível em:

$<$ https://www.revistaensinosuperior.gr.unic amp.br/edicoes/ed06_julho2012/Cibele_Ya hn.pdf>. Acesso em: 21 set. 2017

BRASIL. Lei No 11.340, de 7 de agosto de 2006. Cria mecanismos para coibir a violência doméstica e familiar contra a mulher.

BRASIL. Secretaria Especial de Políticas para as Mulheres - Presidência da República. Norma Técnica de Uniformização dos Centros de Referência de Atendimento à Mulher em Situação de Violência. Brasília, 2006. Disponível em: $<$ http://www.observatoriodegenero.gov.br/ menu/publicacoes/outros-artigos-e-

publicacoes/norma-tecnica-deuniformizacao-centros-de-referencia-deatendimento-a-mulher-em-situacao-de-

violencia/at_download/file> $>$ Acesso em: 15 set. 2017.

BURGOS, M. B. Cidade, Territórios e Cidadania. Revista de Ciências Sociais, Rio de Janeiro, v. 48, n. 1, p. 189-222, 2005. Disponível em:

\section{0}

$<$ http://www.scielo.br/pdf/dados/v48n1/a0 7v48n1.pdf $>$. Acesso em: 29 set.2017.

CARNEIRO, S. Mulheres negras na educação: desafios para a sociedade brasileira. Gênero e educação: fortalecendo uma agenda para as políticas educacionais. São Paulo: Ação Educativa, Cladem, Ecos, Geledés, Fundação Carlos Chagas, p. 121186, 2016. Disponível em: $<\underline{\text { http://generoeeducacao.org.br/wp- }}$ content/uploads/2016/12/generoeducacao site_completo.pdf $>$. Acesso em: 10 set. 2017.

CENTRO DE ESTUDOS DE SEGURANÇA E CIDADANIA - CESeC. Perfil sociodemográfico dos moradores de favelas com UPP na cidade do Rio de Janeiro, 2016. Disponível em: $<$ https://www.ucamcesec.com.br/wpcontent/uploads/2016/03/Perfilsociodemogr\%C3\%A1fico-dos-moradoresde-favelas-com-UPP.pdf $>$. Acesso em: 28 set. 2017.

CORRÊA, R. L. O espaço urbano. São Paulo: Editora Ática, 1989. 94 p. (Série Princípios)

GARCIA, A. S. Contradições na cidade negra: relações de gênero, raça, classe, desigualdades e territorialidade. Saberes em perspectiva, Jequié, v. 2, n. 2, 
jan./abr., p. 33-51, 2012. Disponível em:

$<$ http://www.saberesemperspectiva.com.

br/index.php/saberesemperspectiva/artic

le/view/23>. Acesso em: 10 set. 2017.

GOMES, N. L. Alguns termos e conceitos presentes no debate sobre relações raciais no Brasil: uma breve discussão. In: BRASIL. Educação Anti-racista: caminhos abertos pela Lei federal $\mathrm{n}^{\mathrm{o}} 10.639 / 03$. Brasília, MEC, Secretaria de educação continuada e alfabetização e diversidade, $p$. 39-62, 2005. Disponível em: $<$ http://unesdoc.unesco.org/images/0014/ 001432/143283por.pdf $>$. Acesso em: 10 set. 2017.

GRUPO DE ESTUDOS MULTIDISCIPLINARES DE AÇÃO AFIRMATIVA - GEMAA. Relatório das desigualdades de gênero, raça e classe. Rio de Janeiro, Instituto de Estudos Sociais e Políticos - IESP/UERJ, 2017. Disponível em:

$<\underline{\text { http://gemaa.iesp.uerj.br/relatorios/relator }}$ io-das-desigualdades-gemaa-no-1/>.

Acesso em: 10 set. 2017.

HASENBALG, C.; GONZALEZ, L. Lugar de negro. Rio de Janeiro: Marco Zero, 1982. Disponível em: $<$ https://negrasoulblog.files.wordpress.com /2016/04/lc3a9lia-gonzales-carlos-
111

hasenbalg-lugar-de-negro1.pdf $>\quad$ Acesso em: 15 set. 2017.

MARICATO, Ermínia. As idéias fora do lugar e o lugar fora das idéias. In: ARANTES,

desmanchando consensos. Vozes, Petrópolis, p. 121-192, 2000. $<$ http://labcs.ufsc.br/files/2011/12/07.-

MARICATO-E.-As-id\%C3\%A9ias-forado-lugar-e-o-lugar-fora-dasid\%C3\%A9ias.pdf $>$ Acesso em: 29 set. 2017.

MUSUMECI, L. Perfil sociodemográfico dos moradores de favelas com UPP na cidade do Rio de Janeiro, 2016. Disponível em: $\quad<$ https://www.ucamcesec.com.br/wpcontent/uploads/2016/03/Perfil-

sociodemogr\%C3\%A1fico-dos-moradoresde-favelas-com-UPP.pdf $>$ Acesso em: 28 set. 2017.

SALGUEIRO, T. Cidade pós-moderna: espaço fragmentado. Território, ano $111, \mathrm{n}^{\circ}$ 4, jan./jun. 1998.

SILVA, I. G; SOARES, F. C. O. Violência de gênero e primavera feminista: a alternativa informativa das grandes mídias para as redes sociais. Boletim PROEALC, CCS/UERJ, Rio de Janeiro, n. 72, jun./jul.ago. 2016. Disponível em: 
$<\underline{\text { http://www.proealc.uerj.br/Boletins/docu }}$

mentos/BoletimPROEALC72.pdf $>$ Acesso

em: 10 set. 2017.

VILLAÇA, F. São Paulo: segregação urbana e desigualdade. Estudos Avançados, USP, São Paulo, v. 25, n. 71, p. 37-58, 2011. Disponível em:

$<$ http://www.scielo.br/pdf/ea/v25n71/04.pd f>. Acesso em: 5 out. 2017. 